\title{
Prevention and Treatment of Complications in Proctological Surgery
}

\author{
Mario Pescatori, (c) Springer, 2012
}

\author{
Bruno Roche
}

Published online: 6 March 2012

(C) Springer-Verlag 2012

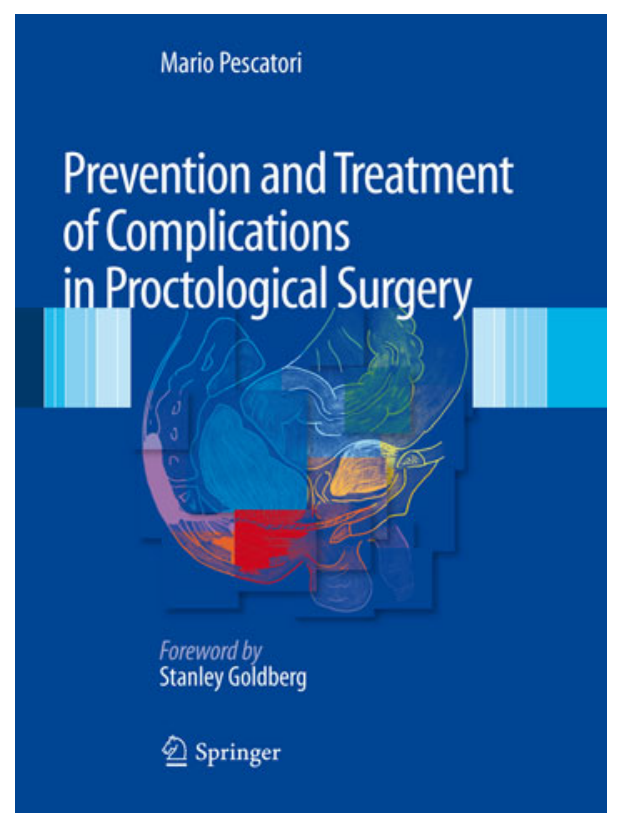

I have been working in the field of proctology since 1992 and have known the author of this book for 20 years. Coming from the University Hospital of Geneva, I receive invitations to present our research and give lectures in many international congresses including those in Italy. Thus, I have many occasions to hear the teachings of Prof. Pescatori and have had numerous opportunities to have discussions with him. Now he has finally put all his valuable knowledge into a book that encompasses his

B. Roche $(\square)$

Unit of Proctology, Department of Visceral Surgery, University Hospital of Geneva, Geneva, Switzerland e-mail: Bruno.roche@hcuge.ch experience in managing and preventing complications in proctology. Such a book has never been written before.

Mario Pescatori is a surgeon who has contributed to the improvement in the knowledge and practice of colorectal surgery over the course of his career. He is not only a surgeon but also a physician and a thinker who uses his experiences and good common sense to find solutions to frequent problems we face in the field of colorectal surgery. He tries to simplify the complexities and find solutions that are practical and easy to remember. Because of his numerous years of practice, his experience is extensive, for example, the evolution of hemorrhoid treatment is covered from $\mathrm{A}$ to $\mathrm{Z}$ including complications seen with PPH and THD. He treats each subject with a very personal touch, and the reader can understand the importance of what he has experienced in order to avoid these situations. It is an honest approach.

As a fellow surgeon and physician, I feel this honest, direct and personal approach to discussing complications is the best way to teach colleagues what to avoid and how to manage problems when they arise. In my own practice, I teach my young doctors that they may only operate with confidence if they are well prepared to manage the complications that may arise and one must remember that even the best surgeons encounter complications. This book is the end result of Prof. Pescatori's years of experience in and reflections on coloproctology. He shares his knowledge with us in order to prevent and treat complications that we all may face in colorectal surgery. As this is the first book ever written on this subject, we can profit from his experiences to enrich our practice of coloproctology. Because of his wealth of knowledge, this book is an indispensible part of the armamentarium of every colorectal surgeon who wants to achieve high standards of surgical practice with a good solid foundation. 